\title{
A folded slot antenna with full ground plane for wearable waterproof wireless sensors
}

\author{
Griffith School of Engineering \\ Griffith University \\ Brisbane, QLD, Australia \\ S2862672@griffithuni.edu.au
}

Mohammad Vatankhah Varnoosfaderani, David V. Thiel, Jun Wei Lu

\begin{abstract}
A 3D dual band slot antenna is presented for waterproof wearable wireless sensors. The size of the antenna is $52 \mathrm{~mm} \times 36 \mathrm{~mm} \times 12 \mathrm{~mm}$ and the slot is etched on the internal walls of a waterproof plastic box which accommodates the sensor electronics. Numerical modeling of the structure against the body revealed a $10 \mathrm{~dB}$ impedance bandwidth of $12.3 \%$ at 2.45 GHz and $21 \%$ at $5.2 \mathrm{GHz}$ respectively. The antenna features a full ground plane underneath which reduces the interaction between the human body and the radiator and so avoids the huge drop in antenna efficiency. The total efficiency of antenna is more than $90 \%$ in free space and reduces to $54 \%$ at $2.45 \mathrm{GHz}$ and $70 \%$ at $5 \mathrm{GHz}$ when located against the body.
\end{abstract}

\section{INTRODUCTION}

Wireless communications has a wide range of applications including sports, mining, health-care etc. The major problem in body worn wireless devices is the negative effect of human body on the performance of device's antenna which causes a significant drop in the signal level and a reduced range of communication. The easiest way to avoid this problem is by using a small antenna with larger ground plane which decreases absorbed power by body and the efficiency of the antenna will not suffer significantly. Flexible microstrip patch antennas have been suggested as the first option for wearable antennas $[1,2]$ because of the full ground plane underneath the antenna. The size of a simple patch antenna is huge compared to the size of the antenna of commercial wireless sensors [3, 4]. Meandered monopole [3] and dipole antennas which are wrapped around wireless sensors [4] are one of the most compact designs. Two different performance criteria for a wearable antenna are: avoiding shift in frequency after putting on the body and, the efficiency of antenna. Total efficiency of antenna includes power return loss and can be considered as the best criterion to investigate the performance of the antenna when it is placed next to body tissues [6]. Dipole antennas which are wrapped around the wireless sensor are compact in size, but the human body can degrade them significantly. Considering the concept of complementary antennas which derives from Huygens' principal, a wrapped dipole antenna can be replaced by a slot in folded metal sheet while having the same radiation features. In this paper a $3 \mathrm{D}$ dual band slot antenna is presented which is boxed in a waterproof wireless sensor container.

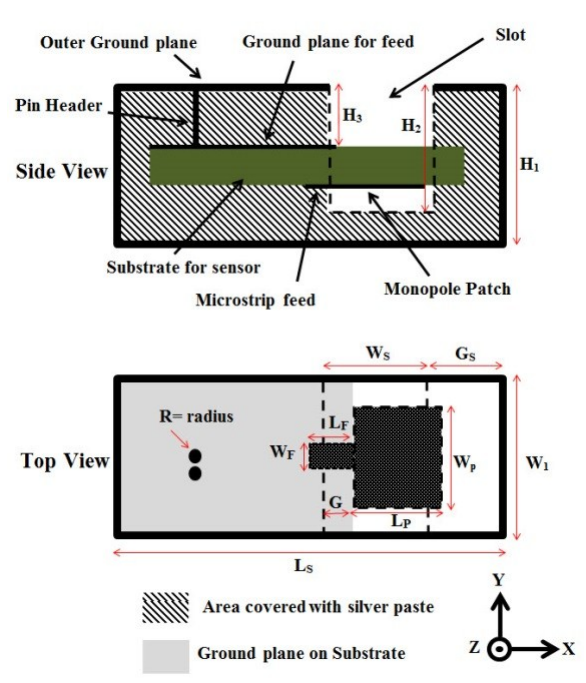

Figure 1: Schematic diagram of the slot antenna wrapped around the sensor

Slot antennas which are fed with a stripline [7] can be considered a good option for wearable application because of the presence of a full ground plane and compact size.

\section{ANTENNA DESIGN}

A small $(36 \mathrm{~mm} \times 54 \mathrm{~mm} \times 12 \mathrm{~mm})$ waterproof $2.45 \mathrm{GHz}$ wireless sensor with a standard meander line printed monopole was designed and fabricated at Griffith University. The antenna of the sensor has poor radiation characteristics when placed against the human body. A plastic box made of polycarbonate $\left(\varepsilon_{r}=3.4\right)$ is used as waterproof cover for the wireless sensor.

The internal walls of the box are covered with silver paste and a slot is cut on top wall of the sensor to form a slot. A simple miniaturized patch monopole, which is quarter of $\lambda_{0}$ in length, using the structure presented in [8] is suspended in the box via two pin headers to feed the slot. The length of the slot is designed to be half of $\lambda_{0}$ at $2.45 \mathrm{GHz}$ and it is wrapped around the box to make the size of the antenna compact. Half length of the slot contains $H_{2}, W_{1}$ and $W_{s}$ which determines the resonant frequency at lower frequency band. The optimized sum of $H_{2}, W_{1}$ and $W_{s}$ is 64.9 which agrees with half of $\lambda_{0}$ in free space. 


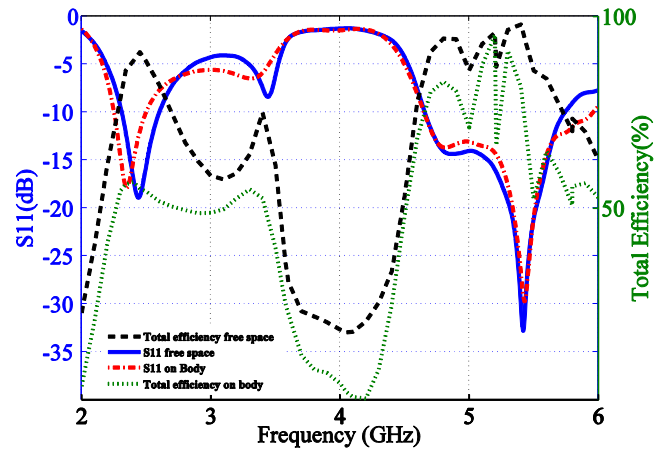

Figure 2: Simulated return loss of and total efficiency of the slot antenna in free space and on the body.

The bandwidth of antenna at $2.45 \mathrm{GHz}$ decreases by narrowing $W_{s}$ which agrees with the same trend of a flat dipole. Parameters in table 1 are optimized to maximize radiation efficiency and minimize return loss in desired frequency bands. The structure of the antenna is shown in figure. 1 and optimized dimensions are presented in Table.1. The radius of via is 0.3 $\mathrm{mm}$.

Table 1: Optimized dimensions of antenna (Dimensions in $\mathrm{mm})$

\begin{tabular}{|c|c|c|c|c|c|c|c|}
\hline $\mathrm{W}_{\mathrm{s}}$ & 17.7 & $\mathrm{~W}_{\mathrm{p}}$ & 18.6 & $\mathrm{~L}_{\mathrm{f}}$ & 9 & $\mathrm{H}_{1}$ & 10 \\
\hline $\mathrm{G}_{\mathrm{s}}$ & 6 & $\mathrm{~L}_{\mathrm{p}}$ & 16 & $\mathrm{~L}_{\mathrm{s}}$ & 50 & $\mathrm{H}_{2}$ & 7.66 \\
\hline $\mathrm{W}_{1}$ & 32 & $\mathrm{~W}_{\mathrm{f}}$ & 3 & $\mathrm{G}$ & 4.67 & $\mathrm{H}_{3}$ & 3.4 \\
\hline
\end{tabular}

\section{SimULATION}

CST Microwave Studio is used to simulate the antenna in free space and next to human body. The body model used in simulation is the Gustav model in the voxel library of CST. To reduce the time of simulation, the body model from chest to stomach was used to decrease number of mesh cells. The simulated return loss and total efficiency of the antenna in free space and next to the body model are depicted in figure. 2 . The antenna is resistant to shifts in the resonant frequency because the ground plane isolates the antenna from the body. Figures 3 and 4 show the radiation pattern of the slot antenna for different conditions and frequency in both the $\mathrm{XZ}$ and $\mathrm{YZ}$ planes.

\section{CONCLUSION}

A compact monopole patch antenna is suspended in a plastic waterproof box of a wireless sensor to feed a slot which is painted using silver paste on internal walls of the box. $10 \mathrm{~dB}$ impedance bandwidth of $12.3 \%$ at $2.45 \mathrm{GHz}$ and $21 \%$ at 5.2 $\mathrm{GHz}$ are achieved respectively. Two simulations including body model and without body model are done to investigate the effects of body on the performance of antenna. The total efficiency of antenna is more than $90 \%$ in free space and reduces to $54 \%$ at $2.45 \mathrm{GHz}$ and $70 \%$ at $5 \mathrm{GHz}$ when located against the body.

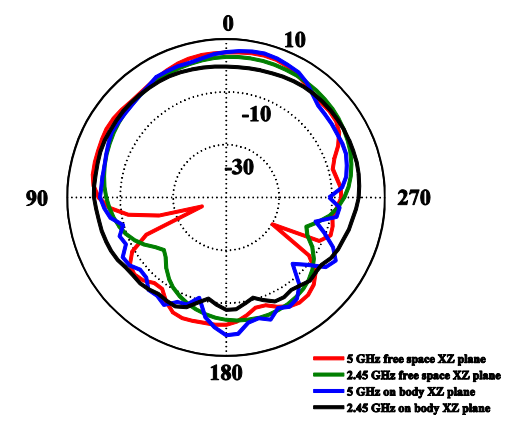

Figure 3: Radiation pattern in $\mathrm{XZ}$ plane

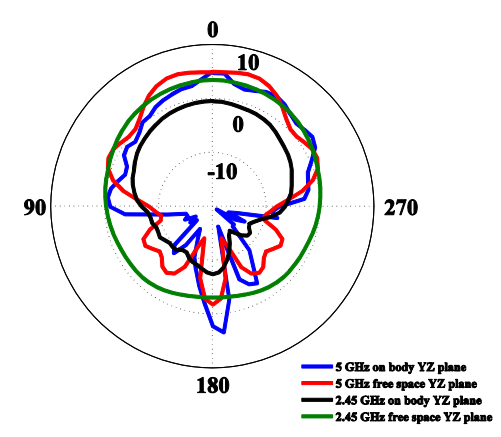

Figure 4: Radiation pattern in YZ plane

\section{REFERENCES}

[1] P. Salonen, K. Jaehoon, and Y. Rahmat-Samii, "Dual-band E-shaped patch wearable textile antenna," in Antennas and Propagation Society International Symposium, 2005 IEEE, 2005, pp. 466-469 Vol. 1A.

[2] P. Salonen, M. Keskilammi, and L. Sydanheimo, "A low-cost $2.45 \mathrm{GHz}$ photonic band-gap patch antenna for wearable systems," Eleventh International Conference on Antennas and Propagation, Vols 1 and 2, pp. 719-723, 2001.

[3] D. A. James, R. I. Leadbetter, M. R. Neeli, B. J. Burkett, D. V. Thiel, and J. B. Lee, "An integrated swimming monitoring system for the biomechanical analysis of swimming strokes," Sports Technology, vol. 4, pp. 141-150, 2011/08/01 2011.

[4] A. Alomainy, Y. Hao, and F. Pasveer, "Numerical and Experimental Evaluation of a Compact Sensor Antenna for Healthcare Devices," IEEE Transactions on Biomedical Circuits and Systems, vol. 1, pp. 242-249, Dec 2007.

[5] C. Huey-Ru and C. Wen-Tzu, "Computer simulation of the human-body effects on a circular-loop-wire antenna for radio-pager communications at 152, 280, and $400 \mathrm{MHz}$," Vehicular Technology, IEEE Transactions on, vol. 46, pp. 544-559, 1997.

[6] S. Xiaoyong, L. Gang, and R. M. Jayasuriya, "A compact broadband stripline-fed slot antenna for array application," in Antenna Technology: Small Antennas and Novel Metamaterials, 2005. IWAT 2005. IEEE International Workshop on, 2005, pp. 555-558.

[7] A. Ghobadi, C. Ghobadi, and J. Nourinia, "A Novel Band-Notched Planar Monopole Antenna for Ultrawideband Applications," Antennas and Wireless Propagation Letters, IEEE, vol. 9, pp. 608-611, 2010. 